\title{
Educação ambiental crítica: revisitando os pressupostos de Paulo Freire e Enrique Dussel
}

\author{
André Luis Castro de Freitas ${ }^{1}$ \\ Luciane Albernaz de Araujo Freitas ${ }^{2}$
}

\begin{abstract}
RESUMO
$\mathrm{O}$ artigo tem como objetivo constituir aproximações entre o campo da educação ambiental crítica e os pressupostos de autores como Paulo Freire e Enrique Dussel. A partir de um estudo descritivo crítico, resultante de uma pesquisa de abordagem qualitativa, bibliográfica, tem-se como intenção elencar a relevância no campo das relações educativas, na área da educação ambiental, as categorias: diálogo, alteridade, dialética e situação-limite. Primeiramente, reflete-se sobre o exercício de um caminhar em que os seres humanos se movimentem dialeticamente, conduzidos pela palavra do Outro. Na segunda parte, faz-se uma discussão sobre a presença na educação da práxis social como processo de reflexão sobre a vida e a natureza, no que implique a ação de transformar a realidade. Por fim, realizam-se reflexões de como a partir das categorias elencadas, por meio de uma educação ambiental crítica, é possível fazer frente à manipulação e aos efeitos produzidos pelo modelo civilizatório em curso.
\end{abstract}

PALAVRAS-CHAVE: Diálogo. Alteridade. Dialética. Situação-limite.

\section{Critical environmental education:}

revisiting the assumptions of Paulo Freire and Enrique Dussel

\footnotetext{
1 Doutor em Educação. Universidade Federal do Rio Grande - FURG, Rio Grande, RS, Brasil. Orcid: http://orcid.org/0000-0002-4566-3655. E-mail: dmtalcf@ furg.br.

2 Doutora em Educação Ambiental. Instituto Federal Sul-rio-grandense - IFSUL, Pelotas, RS, Brasil. http://orcid.org/0000-0001-9014-0071. E-mail: lucianel1968@gmail.com.
} 


\begin{abstract}
The article aims to establish approximations between the field of critical environmental education and the assumptions of authors such as Paulo Freire and Enrique Dussel. Based on a critical descriptive study, resulting from a qualitative, bibliographic research approach, it is intended to list the relevance in the field of educational relations, in the area of environmental education, the categories: dialogue, alterity, dialectics, and limit-situation. First, it reflects on the exercise of a walk-in in which humans move dialectically, driven by the word of the Other. In the second part, there is a discussion about the presence in the education of social praxis as a process of reflection on life and nature, in what involves the action of transforming reality. Finally, reflections are made of how from the categories listed, through critical environmental education, it is possible to face the manipulation and effects produced by the civilization model in progress.
\end{abstract}

KEYWORDS: Dialogue. Alterity. Dialectics. Limit-situation.

\title{
Educación ambiental crítica:
}

revisando los presupuestos de Paulo Freire y Enrique Dussel

\section{RESUMEN}

El artículo tiene como objetivo crear aproximaciones entre el campo de la educación ambiental crítica y los fundamentos de autores como Paulo Freire y Enrique Dussel. Basado en un estudio descriptivo crítico, resultante de una investigación cualitativa, bibliográfica, la intención es enumerar la relevancia en el campo de las relaciones educativas, en el área de educación ambiental, las categorías: diálogo, alteridad, dialéctica y situacione límite. . Al principio, se refleja en el ejercicio de una caminata en la que los seres humanos se mueven dialécticamente, guiados por la palabra del Otro. En la segunda parte, se discute la presencia en la educación de la praxis social como un proceso de reflexión sobre la vida y la naturaleza, en lo que implica la acción de transformar la realidad. Finalmente, se hacen reflexiones sobre cómo, con base en las categorías enumeradas, a través de la educación ambiental crítica, es posible enfrentar la manipulación y los efectos producidos por el modelo civilizador actual.

PALABRAS CLAVE: Diálogo. Alteridad. Dialéctica. Situacione límite. 


\section{Considerações iniciais}

Os problemas socioambientais, enfrentados pela sociedade contemporânea, não se limitam a questões referentes exclusivamente ao meio-ambiente, tal que não se trata somente de uma dificuldade de caráter cultural ou comportamental, mas de uma crise no modelo civilizatório associada à lógica de produção capitalista.

A expansão da produção capitalista está atrelada a um crescimento econômico ilimitado o qual exerce pressão sobre a utilização dos recursos naturais e sobre a capacidade de suporte a vida no planeta. Nesse contexto, a natureza é transformada pelos seres humanos ${ }^{3}$ por meio de suas atividades e esses, no momento em que não possuem uma organização racional, exploram os recursos naturais até a sua exaustão, desencadeando, a partir dessa última, diversas catástrofes.

Assim, o sistema em curso faz com que os seres humanos ignorem os nexos ecológicos, não percebendo, ainda, a necessidade de reformulação das relações entre a dinâmica socioeconômica e os fenômenos naturais. Inserido nessa discussão, Leff (2000) reflete que a crise no modelo civilizatório “[...] não só se manifesta na destruição do meio físico e biológico, mas também na degradação da qualidade de vida, tanto no âmbito rural como no urbano" (LEFF, 2000, p. 41).

Contudo, acredita-se que não basta rever somente as ligações entre os seres humanos e a natureza, mas se faz necessário constituir um novo olhar para as relações entre os sujeitos, relações essas prejudicadas no momento em que refletem atitudes e comportamentos irracionais, pois a dominação destrutiva torna-se a base dessas, tendo sua origem em vínculos de poder historicamente constituídos.

\footnotetext{
${ }^{3}$ Acompanhando as ideias freirianas, ao longo do texto será utilizado o termo ser humano como forma de abranger as questões de gênero. O termo homem foi utilizado por Freire no sentido genérico com o significado de homem e mulher, mas, a partir da obra Pedagogia da esperança: um reencontro com a pedagogia do oprimido, o autor fez a alusão, específica, ao gênero feminino. "Daquela data até hoje me refiro sempre a mulher e homem ou seres humanos. Prefiro, às vezes, enfeiar a frase explicitando, contudo, minha recusa à linguagem machista” (FREIRE, 2002, p. 68).
} 
Aproximando ao campo da educação ambiental, a intencionalidade do texto aqui proposto, fundamentado a partir de uma pesquisa qualitativa, de base bibliográfica, é problematizar a partir dos pressupostos de Paulo Freire e Enrique Dussel as categorias diálogo, alteridade, dialética e situaçãolimite, no que implique mediar e gerar ações transformadoras no e com o mundo, refletindo sobre as práticas dessas ações.

$\mathrm{O}$ texto está descrito da seguinte forma: $\mathrm{O}$ respeito à vida - reflete-se, no que pese o contexto de uma educação ambiental crítica, sobre o exercício de um caminhar em que os seres humanos se movimentem dialeticamente, conduzidos pela palavra do Outro, em direção a um novo projeto de vida; $\mathrm{O}$ papel da educação frente à crise socioambiental - faz-se uma discussão sobre a presença na educação da práxis social como processo de reflexão sobre a vida e a natureza, no que implique a contribuição de como transformar a realidade; As desigualdades socioculturais e a educação ambiental realizam-se reflexões de como a partir das categorias elencadas, por meio de uma educação ambiental crítica, é possível fazer frente à manipulação e aos efeitos produzidos pelo modelo civilizatório em curso. Após o tratamento desses aspectos, seguem as considerações finais.

\section{$O$ respeito à vida}

Na obra de Paulo Freire, pela relação dialógica, a subjetividade se converte em subjetividade humana, no momento em que denota a importância ao ser humano e o diálogo não se constitui fundamentado na razão pura, mas na possibilidade de ouvir o Outro. O mesmo autor reflete sobre a criação de espaços para o exercício da ação de aproximar e conhecer os sujeitos, proporcionando uma atmosfera de intimidade entre esses, tal que nessa relação todo o ser humano se constitui com o Outro, com identidade, e não como desconhecido.

Dessa maneira, reflete-se sobre a importância ao acatamento e ao respeito em relação ao Outro, como princípios fundantes de uma relação. 
Freire (2014), na obra Pedagogia da indignação, acrescenta que além de reverenciar a vida humana deve-se, também, reverenciar a vida “[...] vegetal e animal, o cuidado com as coisas, o gosto da boniteza, dos sentimentos" (FREIRE, 2014, p. 77). Resume dessa forma, a necessidade de que os seres humanos lutem pelos princípios éticos fundamentais como o respeito à vida humana, aos animais e ao ambiente tal que conclama, a todos, ao desenvolvimento da capacidade de amar o mundo ${ }^{4}$.

Nessa esteira, Freire reflete que a ecologia ${ }^{5}$ ganha uma importância fundamental e que deve estar presente nas práticas educativas críticas e libertadoras, pois essa remete a ação de problematizar as relações entre os seres vivos entre si e, ainda, desses com o meio. Tal concepção de estudar as relações dos seres com e no mundo implica em analisar os aspectos sociais, culturais, políticos e econômicos.

De mesma maneira, a preocupação com a vida também está presente na obra de Enrique Dussel. Para esse autor se há uma história do mundo existe, também, uma história da natureza e essa para a modernidade europeia, juntamente, com o trabalho e o capital foram os constituintes da origem do progresso civilizatório. Com isso, a natureza continua economicamente explorada desde a Revolução Industrial, e também “[...] politicamente interpretada; é hermeneuticamente visualizada desde o centro ou a periferia, desde as diversas classes sociais, desde os sistemas políticos, principalmente, como matéria de um modo de produção numa formação socialmente determinada" (DUSSEL, 1977, p. 114-115).

Tendo como alinhamento a expansão colonial, momento em que o poder encontrava-se dividido entre a aristocracia e a burguesia, a qual

\footnotetext{
${ }^{4}$ Para Andreola (2010), Paulo Freire “[...] relaciona a categoria mundo com: a natureza, cultura, história, existência, consciência, trabalho, ação transformadora, palavra e práxis, conceitos através dos quais ele tenta explicar a relação dialética: leitura do mundo - leitura da palavra, fundamento de toda a alfabetização e de toda a educação" (ANDREOLA, 2010, p. 283). Segundo o mesmo autor, para o ser humano, o mundo significa o contexto de sua existência, transformando esse contexto por sua ação.

${ }^{5}$ Mesmo que Freire utilize o conceito ecologia, conforme Delizoicov e Delizoicov (2014), a proposta freiriana está alinhada a um estilo de pensamento crítico-transformador em que a concepção de meio ambiente diz respeito a um dado lugar em que os elementos naturais e sociais constituem relações e estão em interação. Tais relações implicam em processos culturais, sociais e históricos de transformação do meio. Por outro lado, segundo os mesmos autores, o estilo de pensamento ecológico é o estudo da natureza, da fauna e da flora, a natureza e os elementos que a cercam.
} 
gradativamente se impunha pela força do capital, tem-se claro que a promessa da modernidade era direcionada aos sujeitos da Europa Ocidental, aos representantes dessas duas classes.

A colonização dos novos continentes pelos europeus foi encharcada por essa concepção hierárquica, na qual os povos colonizados foram tratados como se fossem seres inferiores, contribuindo para a estruturação de uma ordem social de desigualdades e injustiças que se perpetuam até os dias atuais. Essa situação se propaga de mesma maneira, para o campo ambiental, produzindo a situação de que a crise ambiental assume diferentes dimensões para as distintas classes sociais, afetando, de forma mais drástica, os países mais pobres e as classes desfavorecidas.

O respeito à vida das classes desfavorecidas, torna necessário pensar em mudanças radicais as quais fundamentem a construção de outro modelo societário a fim de eliminar os mecanismos responsáveis pelas desigualdades e injustiças, como é o caso da exploração econômica, concentração de renda entre tantos outros fatores que acompanham os processos de apropriação privada dos bens materiais.

Para Layrargues (2006) é necessária a construção de uma sociedade ecologicamente criteriosa e responsável e, ainda, socialmente justa tendo a dialética como estratégia de mediação entre a mudança social e a mudança cultural. Porém, o autor enfatiza que a mudança só se faz possível no momento em que se leva em consideração a sociedade da qual se é parte, pois os valores são “[...] definidos a partir de condições históricas específicas, inseridas num mundo dialético de mútua constituição entre objetividade e subjetividade" (LAYRARGUES, 2006, p. 13).

Outro ponto que merece destaque é o exercício de refletir sobre o problema ambiental de forma articulada com a totalidade das dimensões da sociedade, pois a não articulação resulta em uma visão dualista de mundo, em que “[...] a luta pela proteção da natureza sobressai como algo hierarquicamente prioritário sobre a luta por justiça e igualdade 
social, em vez de serem percebidas como intrinsecamente vinculadas" (LAYRARGUES, 2006, p. 14).

A compreensão das relações entre objetividade e subjetividade para Freire (1980, 2011, 2014) é dialética, não mecânica, no sentido de constituir o pensar e o atuar na realidade para que se possa transformá-la. Nessas condições, para o autor não é possível aceitar a subjetividade de maneira idealista, em que a força da consciência seria condição para modificar o mundo, nem tampouco, do ponto de vista mecanicista em que a subjetividade representaria o reflexo das condições materiais, tal que ao transformar a objetividade ter-se-ia modificado a subjetividade.

A partir dessa perspectiva, compreende-se que a educação ambiental não possa restringir-se como aquela que oculta às contradições da realidade, mas considerando a sua dimensão ético-política deve estar a serviço de contribuir para a solução dos problemas gerados pelo modelo civilizatório em curso, no momento em que o sistema capitalista ameça a sobrevivência de todos.

Assim, a educação ambiental crítica deve estar a favor de compreender as relações entre a consciência e o mundo, inserida em um contexto em que a educação represente um processo de "[...] denúncia da realidade perversa como do anúncio da realidade diferente a nascer da trasnformação da realidade denunciada” (FREIRE, 2014, p. 102).

Ao considerar-se uma perspectiva dialética o mundo e a consciência se dão simultaneamente, pois a consciência do mundo constitui a consciência do Eu e dos Outros no mundo, mediatizados por esse. Assim, é na inserção no mundo como seres condicionados e não na adaptação que os sujeitos se tornam seres históricos e éticos, com a capacidade de decidir e romper com a realidade, criando processos de transformação no cotidiano.

Freire (2004) assume sua opção ao termo condicionado, por crer que ao sujeito imerso em uma situação de opressão lhe será exigida a ação, desde que possuidor da capacidade de reflexão e tomada de consciência. A proposta freiriana não está alinhada a um ser determinado, pois, como tal, esse não vislumbra alternativas de transformação social, econômica e, ainda, política. 
Dussel $(1974,1977)$, de mesma maneira, defende um movimento para além do mecanicismo e do idealismo, no momento em que faz uma crítica a filosofia latino-americana a qual deveria estar centrada na possibilidade de pensar o movimento dialético de libertação, em como libertar o ser humano em todos os níveis culturais, ou seja, libertar seu ser negado.

Para o autor, o método dialético engloba os momentos: negativo ${ }^{6} \mathrm{e}$ positivo $^{7}$, em uma unidade totalizadora e sempre intotalizada, em um movimento que tende à exterioridade sem abarcá-la. Assim, o método é um momento da realidade dialética em constante processo de mediação. A mediação implica um compromisso existencial, pela práxis libertadora, por um tornar próprio o mundo do Outro, instante em que é possível alcançar a interpretação, a conceitualização e a verificação de sua revelação.

Nessa etapa de mediação, Dussel (1977) determina como momento analético do método dialético aquele em que o ser humano caminha em direção a libertação do Outro alcançando a própria liberdade. Na analética a partir da aceitação ética da interpretação do oprimido, mediada pela práxis, o seres humanos constituem a condição de possibilidade de compreensão e de esclarecimento, fruto de terem ascendido à exterioridade, "[...] único âmbito adequado para o exercício da consciência crítica” (DUSSEL, 1977, p. 164).

Nessas condições, problematizar uma educação ambiental transformadora exige partir de uma situação concreta, e pela atitude crítica, em exercício da autoconsciência da alienação, da opressão, reconhecendo, ainda, sofrer a dominação, pensar e agir sobre essa opressão e sobre essa libertação. O ato de pensar, finalmente, remete a construir um caminhar em que os seres humanos se movimentem dialeticamente em direção a um novo projeto, sempre conduzidos pela palavra do Outro. Com o objetivo de refletir

\footnotetext{
${ }^{6} \mathrm{O}$ momento dialético negativo implica trabalhar a categoria totalidade em que se estabelece a dialética do mesmo, pois se trata de uma categoria unidimensional, única, a qual define a partir do sujeito a identidade e a diferença, tornado-se o fim do discurso, e impossibilitando o diálogo com a alteridade.

7 O momento dialético positivo implica, semanticamente, o Outro. A categoria própria do momento positivo é a exterioridade tal que o ponto de partida do discurso passa a ser a exterioridade do Outro e seu princípio é a distinção, a separação, e não mais a identidade, possibilitando o diálogo com alteridade.
} 
sobre a construção desse novo projeto, a próxima discussão visa apresentar o papel da educação frente a crise socioambiental.

\section{O papel da educação frente à crise sócioambiental}

Refletir sobre a superação da crise socioambiental é promover o pensar para além de mudanças de caráter apenas conjuntural, pois essas não abalam os mecanismos de reprodução social mantendo inalteradas as relações de poder. Principiando por essa premissa acredita-se que o papel da educação ambiental crítica, a qual deverá partir de uma situação concreta, ou seja, o esgotamento das condições materiais do planeta e suas decorrências, tendo como base ontológica e gnosiológica, o materialismo histórico e dialético, é propor o entendimento da “[...] educação não como o único meio para a transformação, mas como um dos meios sem o qual não há mudança” (LOUREIRO, 2006, p. 58).

Compreender a educação ambiental crítica em sua amplitude e complexidade permite fazer de seus pressupostos balizadores a construção de uma educação e, sobretudo, de uma prática pedagógica que esteja em sintonia com os anseios de contribuir com o processo contra-hegemônico.

Nesse contexto, aproximam-se as relações educativas propostas por Freire, o qual parte do princípio de que a educação é um caminho para que os seres humanos formem uma consciência crítica diante dos problemas da realidade e possam agir no sentido de transformá-la. Nesse caso, o papel do educador é promover a apreensão da realidade em partilha com os educandos, estando aberto a um, permanente, aprender e ensinar.

Para Freire (2004), na obra Pedagogia do oprimido, o diálogo passa a existir na relação do educador com os educandos, momento esse em que se constitui a partilha das visões de mundo, pois é pela situação presente, concreta, na reflexão das aspirações dos seres humanos, que se poderá organizar o conteúdo programático. Dessa maneira, nasce a problematização do tema gerador a partir da constituição do universo mínimo temático. 
Esse universo mínimo é composto por temas os quais, em geral, se contradizem e, por vezes, mantêm estruturas já existentes, nas quais se estabelece uma relação de correspondência entre os temas geradores e a realidade da qual os sujeitos fazem parte, possibilitando perceber a inserção dos envolvidos na temática.

Freire (2004) argumenta que os temas geradores, não raro, encontram-se encobertos pelo que compreende como situações-limites, as quais se apresentam como determinantes históricas, provocando aos sujeitos uma adaptação à realidade em que se encontram. Para o autor, no momento em que, na ação, se instaura a percepção crítica irá “[...] se desenvolver um clima de esperança e confiança que leva os homens a se empenharem na superação das 'situações-limites"' (FREIRE, 2004, p. 91, grifo do autor).

Dessa maneira, a proposta freiriana indica que a percepção dos temas geradores acabe por acontecer quando os sujeitos, ao mesmo tempo, percebem que os temas estão envolvidos e, ainda, envolvem as situaçõeslimites, estabelecendo uma dimensão crítica. Pensar a liberdade do ser humano remete às condições de lugar e tempo nas quais as situaçõeslimites estão vinculadas à criação de novas possibilidades de transformação, e não ao enclausuramento dessas.

Compreende-se que os seres humanos, diante das situações-limites, constroem um projeto de superação e, por esse motivo, Freire sinaliza o alerta de que esses sujeitos estejam envolvidos e envolvam as situaçõeslimites, para que somente dessa maneira o projeto de superação seja executado pelos atos-limites. Para Pinto (1960, v.2), os atos-limites possuem por objetivo produzir o rompimento dos limites, pois "[...] promovem o futuro, projetando-o e projetando-se nele, na negação objetiva da 'situaçãolimite"' (PINTO, 1960, v.2, p. 285, grifo do autor).

Com o intuito de desvelar a realidade social, Freire enfatiza a necessidade de propor aos sujeitos as dimensões significativas ${ }^{8}$ de sua

\footnotetext{
${ }^{8}$ Para Freire (2004), as dimensões significativas representam temáticas socias, econômicas, políticas ou existenciais a serem discutidas em partes que interagem, sendo percebidas pelos seres humanos como uma totalidade da realidade
} 
realidade, "[...] cuja análise crítica lhes possibilite reconhecer a interação de suas partes" (FREIRE, 2004, p. 96).

A captação e a compreensão da realidade percebida se refazem, e os seres humanos passam a entender que a razão da realidade não está fora dela, não se encontra dicotomizada. O processo de percepção da realidade social permitirá a superação do conhecimento abstrato isolado das partes e, também, a superação do conhecimento dedutivo dessa mesma realidade.

A investigação do tema gerador compreende que os sujeitos se assumam ativos, compartilhando na diferença, na qual o investigar, como radicalidade crítica, significa a atuação dos seres humanos sobre a realidade. Assim, o concreto e o abstrato se movimentam, possibilitando um novo concreto. "Isto não significa a redução do concreto ao abstrato, mas têlos como opostos que se dialetizam no ato de pensar" (FREIRE, 2004, p. 97).

O processo educativo freiriano faz com que os seres humanos se desloquem por entre o concreto e o abstrato retornando ao concreto concebido pelo pensamento, caracterizando um movimento por entre abstrato e concreto no qual se supera a abstração pela percepção crítica do concreto.

Já o processo educativo, abordado por Dussel (1986) está centrado no momento em que o autor se refere ao Outro como distinto, como polo livre, não como o Mesmo. Assim, enquanto distinto, o ser humano, como educando, possui um novo projeto de ser sujeito histórico tal que o educador deve ensinar o já adquirido a partir da situação existencial do sujeito fazendo com que a "[...] revolução criadora chegue a confundir-se com a própria invenção problematizadora do educando" (DUSSEL, 1986, p. 133). Reflete, ainda, que o educador aprende, concomitantemente, o projeto do educando, ou seja, o mesmo do Outro, o novo que o educador ignorava.

Assim, o educando aprende a palavra autêntica do educador lançando seu mundo, seu projeto, em um movimento que significa a própria realização,

social. "Desta maneira, as dimensões significativas, que por sua vez, estão constituídas de partes em interação, ao serem analisadas, devem ser percebidas pelos indivíduos como dimensões de totalidade. Deste modo, a análise crítica de uma dimensão significativo-existencial possibilita aos indivíduos uma nova postura, também crítica, em face das 'situações-limites'" (FREIRE, 2004, p. 96, grifo do autor). 
mas ao mesmo tempo lhe exige que se abra ao Outro, que foi revelado pelo educador. O educador aprende a partir da novidade do projeto do Outro, pois esse projeto originou-se em um dado momento histórico e, consequentemente, o educando aprende a partir do exercício da alteridade por parte do educador.

A alteridade é uma categoria fundamental no contexto dusseliano tal que se caracteriza como a "[...] "passagem diacrônica, desde o ouvir a palavra do outro até a adequada interpretação” (DUSSEL, 1986 , p.208) do mesmo, de acordo com uma ética pressuposta no ser humano. Dussel afirmase no exercício do ouvir o Outro pelo compromisso existencial.

Para Freire e Dussel, o reconhecimento da alteridade, da diferença, é condição constituinte do próprio Eu e do Outro, os quais se constituem na relação, na intersubjetividade, tal que o Eu somente existe a partir do Outro.

Ao alinhar a discussão dos autores, retomando, ainda, Loureiro (2006), compreende-se a necessidade da presença na educação ambiental crítica e popular da práxis social como processo de reflexão sobre a vida e a natureza, no que implique a contribuição de como transformar o modo como os seres humanos existem e estão no mundo. Nessas condições, a educação ambiental crítica torna-se uma categoria teórico-prática da educação.

Inserido nesse contexto, a próxima discussão possui por objetivo apresentar uma reflexão sobre as desigualdades socioculturais, tendo como origem as contradições do modelo civilizatório.

\section{As desigualdades socioculturais e a educação ambiental}

A lógica do processo de produção capitalista, na qual os altos níveis de consumo e os grandes impactos ambientais não perpassam as diferentes camadas sociais de forma homogênea, configura-se por relações de poder assimétricas. Em consequência, o acesso, a apropriação e o uso dos recursos ambientais associado a uma lógica de autorregulação do mercado, a partir de valores competitivos e individualistas, determinam a organização da sociedade que tem na lucratividade sua lógica. 
As desigualdades sociais oriundas do desenvolvimento do modelo civilizatório se alastram para a dimensão ambiental, estabelecendo, na visão de Layrargues (2006), materialidade a uma nova desigualdade. Segundo o autor essa materialidade se expressa no conceito de vulnerabilidade ambiental que atinge grupos sociais em condições de vulnerabilidade social, econômica e política, tendo suas condições de vida ou de trabalho ameaçadas pela degradação ambiental, causada pela exploração dos recursos naturais de maneira indevida.

Para Herculano (2002), a existência crescente dessa desigualdade é chamada de injustiça ambiental, definida como o "[...] mecanismo pelo qual sociedades desiguais destinam a maior carga dos danos ambientais do desenvolvimento a grupos sociais de trabalhadores, população de baixa renda, grupos raciais discriminados, populações marginalizadas e mais vulneráveis” (HERCULANO, 2002, p. 19).

Os autores defendem, nesse caminho, a existência de uma relação entre "[...] baixa condição socioeconômica e alta exposição aos riscos ambientais, [...] causando injustiça ambiental para uns e conforto ou segurança ambiental para outros" (LAYRARGUES, 2006, p. 19). Assim, torna-se evidente a conexão existente entre a crise ambiental e um contexto amplo envolvendo as dimensões: econômica, política e social as quais fazem parte do modelo civilizatório.

O modelo civilizatório estabelece uma relação entre os seres humanos e a natureza que não é inata desses, mas resultado dos vínculos sociais impostos pelo capital. Tal relação é mediada pelo trabalho, que se torna prática alienante quando da dissociação do trabalhador de sua produção, pela venda da força do trabalho, transformando-o em simples mercadoria. A relação mercantil compromete a unicidade entre os seres humanos e a natureza, gerando a exploração até o esgotamento tanto da natureza como dos sujeitos enquanto força de trabalho.

Nessas condições, a pressão humana sobre os ecossistemas se dá de forma muito irregular, isto é, uma pequena minoria dos seres humanos consome grande parte das matérias-primas e energias produzidas. Assim, é 
possível concluir que, para a garantia desse alto padrão de vida da minoria torna-se necessário lançar mão de altos níveis de recursos materiais, os quais comprometem a sustentabilidade da vida dos demais que não usufruem das benesses de uma vida de riqueza.

Associado a essas sinalizações, Layrargues (2018) afirma que no momento contemporâneo a educação ambiental foi atravessada pelo signo do antiecologismo ${ }^{9}$, período em que foi consolidado um conservadorismo pedagógico, tornando essa educação hegemonicamente reprodutivista, implicada, de maneira generalizada, como os valores de sociabilidade do capital, omitindo, por sua vez, o quadro histórico-crítico que contribui para os esclarecimentos sobre as contradições da sociedade capitalista.

Assim, a educação ambiental foi modificada para contribuir com o processo de estabelecimento de um padrão normal a ser cumprido, em favor de uma identidade pacificada e controlada, um modo de comportamento ecologista desejável, moderado, desqualificando, ao final, o pensamento crítico.

Para o mesmo autor, essa educação ambiental reprodutivista tornouse dissimulada como aquela que possui uma intencionalidade persuasiva e domesticadora dos sujeitos, passando a disseminar ideias convenientes ao capital e, ainda, apresentando a problemática ambiental segundo a visão do ambientalismo de mercado. Dessa maneira, passou a oferecer soluções aos desafios ambientais que favorecem ao mercado, apresentando um modelo de sujeito ecológico identificado como o ambientalista moderado, ou seja, aquele que se preocupa em fazer a sua parte na sociedade, disposto, individualmente, a mudar seus hábitos de consumo e descarte.

Os problemas dissertados até aqui representam o que se poderia chamar de situações-limites da dimensão socioambiental, momento em que há a necessidade de questionar em que medida é possível a criação de novos encaminhamentos para os seres humanos, no que implique as relações

\footnotetext{
${ }^{9}$ Para Layrargues (2018), o antiecologismo representa o retorno da prevalência econômica, em nome de um ajuste com vistas a reequilibrar a relação entre economia e ecologia. Para o autor, "[...] a narrativa de sustentação do antiecologismo se baseia nos excessos cometidos na era ambiental pelo ecologismo ter sido excessivamente rigoroso com a criação de todo um aparato político-institucional de proteção ambiental, que não mais deveria inviabilizar o crescimento econômico" (LAYRARGUES, 2018, p. 33).
} 
desses no e com o mundo? Deve-se levar em consideração que a educação ambiental passa por um momento em que está presente a dicotomia entre a ação de preservar posta em uma educação que anuncia boas práticas individuais e a ação de transformar a realidade inserida em uma educação que denuncia a insustentabilidade.

Para reafirmar a discussão, retomam-se as categorias elencadas, iniciando pela dialética, tal que há a necessidade de superação dessa dicotomia entre uma educação em defesa dos caminhos alternativos de sustentabilidade e, ao mesmo tempo, outra que trate o combate ao caminho hegemônico da insustentabiliade.

Anúncio e denúncia implicam a leitura da realidade e a prática educativa será mais eficaz, não reprodutivista, na medida em que possibilitar aos seres humanos o acesso as categorias fundantes como o diálogo e a alteridade no campo da educação ambiental crítica e, ainda, no momento em que esses mesmos sujeitos sejam desafiados a construirem uma compreensão crítica do mundo. Essa prática educativa histórica e cultural, implicada com as condições concretas da realidade, constitui uma educação como caminho em pról das transformações sociais.

Não é possível deixar de refletir que os seres humanos estão tomados por fragmentos impostos pelos modelos de produção e consumo vigentes. Fragmentos esses os quais geram minorias culturais diversificadas, tal que nesse momento pares conceituais como universal e fragmento, identidade e diferença, são postos em irreconciliável oposição. Nessa esteira, torna-se premente que os seres humanos envolvidos na relação educativa consigam identificar e discernir as semelhanças e as diferenças presentes no contexto vivido. Nessas condições, o diálogo freiriano, a partir de sua dimensão ontológica, permite que a partilha entre os sujetitos ganhe centralidade, redefinindo o quadro do poder entre os envolvidos.

Freire, com o foco na educação popular, pelo diálogo toma, como ponto de partida, o quadro antropológico-cultural, o qual está, intimamente, ligado à vida daqueles que participam da relação educativa. Nessas condições, o 
universo temático, o mundo da cultura dos sujeitos envolvidos, permite a construção do universo vocabular.

A partir dessas ideias, na relação dialógica, a compreensão do mundo para a sua transformação ganha centralidade, mas, ao mesmo tempo, identificase o alerta da proposta freiriana quanto à existência de um quadro perverso do poder, instituído na luta de classes, tornando necessário que se fundamente as relações educativas partindo, sempre, do mundo da vida das pessoas.

No que pese o mundo da vida, para Dussel o reconhecimento da alteridade, da diferença, é condição constituinte do próprio Eu e do Outro, os quais se constituem na relação, na intersubjetividade, tal que o Eu somente existe a partir do Outro, fazendo com que a relação educativa, nesse contexto, torne-se um compromisso existencial.

Dussel afirma a necessidade de considerar a palavra do Outro como semelhante conservando a distinção metafísica que se apoia nele como Outro, não como idêntico ou unívoco, mas respeitando a analogia da revelação. Assim, a história da libertação humana se faz a partir de resultados relativos, nunca finais de tal maneira que para o autor o caminho é ouvir a voz do pobre, a voz do povo, comprometendo-se com a "[...] humildade e mansidão na aprendizagem pedagógica do caminho de que a palavra do outro, como mestra, vai traçando cada dia" (DUSSEL, 1986, p. 209).

O ser humano como Outro é aquele que representa o centro do seu próprio mundo e mesmo como dominado ou oprimido pode dizer o insperado, o inédito, a palavra que representa a experiência pessoal-coletiva, em seu mundo. Enquanto Outro é um ser livre, já enquanto parte de um sistema torna-se funcional em relação a uma estrutura.

Freire remete ao contexto de aceitar a palavra do Outro compreendendo que como premissa está à ação de saber escutar, o ato de ouvir, como disponibilidade permanente do sujeito que ouve a fala do outro. $\mathrm{O}$ ato de ouvir, no contexto freiriano, está associado ao exercício da humildade, o qual revela de mesma maneira os limites do saber e da ignorância do Eu. Ao considerar as relações educativas, Freire (2003) 
enfatiza a necessidade de respeito e humildade em relação à "[...] identidade do educando, à sua pessoa, a seu direito de ser" (FREIRE, 2003, p. 67).

Tal situação irá garantir a convivência com o direito as diferenças, sem que se exclua o debate, ou seja, o diálogo sobre as diferenças. Aproximando ao afirmado por Dussel, as diferenças estão, justamente, nos contextos vividos pelos seres humanos, em sua cultura, tal que a experiência dialógica se torna uma experiência individual e coletiva.

O diálogo sobre as diferenças abre caminhos ao relato de visões distintas de mundo, aportando os fragmentos referentes à cultura desses sujeitos, promovendo, assim, a partilha a qual irá exercitar a reflexão.

É nessa partilha, que as determinantes históricas tornam-se percebidas, tal que os seres humanos envolvidos e envolvendo as situaçõeslimites passam a instaurar respostas autênticas aos desafios suscitados. Essa reflexão a respeito das situações-limites, a qual não pode se restringir as individualidades, mas a um coletivo, faz com que a percepção da realidade sociocultural avance na superação tanto do conhecimento abstrato isolado das partes como do conhecimento dedutivo dessa mesma realidade.

Assim, a relação educativa, em favor de uma educação ambiental crítica, deve proporcionar à "[...] desmitologização da realidade" (FREIRE, 2011, p. 77), em que o sujeito poderá tomar distância da realidade em que se encontra, para constituir o movimento de inserção crítica nessa mesma, resultando na ação sobre essa realidade constituída. Para além de resultar uma forma de linguagem, o processo busca desvelar as relações dos seres humanos com e no mundo, como modo de ação política, pela consciência de si.

A problematização das situações-limites promove o exercício sobre o pensar diferentes existenciais, possibilitando que os sujeitos se aproximem de sua nova construção, singularizando o processo do qual extraem o problema. É pela constituição dessa singularidade que os seres humanos irão se reconhecer como sujeitos históricos, com possibilidade de ação na realidade.

\section{Considerações finais}


Os pressupostos definidos nas obras de Paulo Freire e Enrique Dussel remetem a reflexão sobre a necessidade de valorização da identidade cultural dos seres humanos, identidade essa a qual anuncia a leitura de mundo exercida por esses sujeitos, não raro, subssumida aos modos de produção e consumo impostos pelo modelo civilzatório.

A discussão elaborada no texto, com o foco voltado ao campo da educação ambiental, enfatiza a necessidade de respeito e entendimento diante dos saberes dos sujeitos, tal que essa educação crítica e popular assume seu papel no momento em que marcha na direção da constituição de uma nova realidade e, ao mesmo tempo, denuncia as estruturas desumanizantes. Para que isso aconteça, o processo educativo deve partir da realidade dos seres humanos, mantendo a constante dialetização entre objetividade e subjetividade.

De maneira resumida, refletiu-se a respeito das seguintes ideias força:

- Diálogo - exige uma escuta da prática, de tal maneira que a relação dialógica possa priorizar a vocação ontológica do ser humano, vocação de ser sujeito, promovendo a compreensão do contexto e dos saberes dos envolvidos na relação;

- Alteridade - define como premissa a necessidade de ouvir o Outro, pois o diálogo deve promover ao sujeito o deixar tomar-se pelas razões do Outro, antes de elaborar a contraposição de ideias, ou seja, o deixar algo em si que foi dito pelo Outro, o exercício da alteridade;

- Dialética - assume a importância da história, bem como, do papel da objetividade e da subjetividade humana na construção do mundo socioculturalmente estruturado, fundamentado nas categorias totalidade e exterioridade; e

- Situação-limite - surge na relação dialógica o debate de temas desafiadores, tal que os seres humanos, pelo diálogo crítico, devem envolver e serem envolvidos pelas situações-limites, recuperando, assim, a vocação 
ontológica do ser mais, como condição fundamental para o respeito e a partilha entre os sujeitos.

Por fim, partindo dos pressupostos aqui explicitados, reflete-se que as obras de Paulo Freire e Enrique Dussel, aproximadas ao campo da educação ambiental crítica, representam marcos conceituais capazes de oferecer sustentação a formação dos seres humanos, formação essa imbricada a transformação social, tal que a apreensão das determinantes históricas seja o foco dessa formação.

\section{Referências}

ANDREOLA, B. Mundo. In: STRECK, D.; REDIM, E.; ZITKOSKI, J.J. (orgs). Dicionário Paulo Freire. 2. ed. Belo Horizonte: Autêntica, 2010. p. 282-283.

DELIZOICOV, D.; DELIZOICOV, N.C. Educação ambiental na escola. In: LOUREIRO, C.F.B; TORRES, J.R. (orgs). Educação ambiental: dialogando com Paulo Freire. São Paulo: Cortez, 2014. p. 81-115.

DUSSEL, E. Método para uma filosofia da libertação. São Paulo: Loyola, 1974.

DUSSEL, E. Filosofia da libertação: Filosofia na América Latina. São Paulo: Loyola, 1977.

DUSSEL, E. Método para uma filosofia da libertação: Superação analética da dialética hegeliana. São Paulo: Loyola, 1986.

FREIRE, P. Conscientização: teoria e prática da libertação: uma introdução ao pensamento de Paulo Freire. 3. ed. São Paulo: Cortez \& Moraes, 1980.

FREIRE, P. Pedagogia da esperança: um reencontro com a pedagogia do oprimido. 9.ed. Rio de Janeiro: Paz e Terra, 2002.

FREIRE, P. Pedagogia da autonomia: saberes necessários a prática educativa. 28. ed. Rio de Janeiro: Paz e Terra, 2003.

FREIRE, P. Pedagogia do oprimido. 38. ed. São Paulo: Paz e Terra, 2004.

FREIRE, P. Ação cultural para a liberdade e outros escritos. 14. ed. Rio de Janeiro: Paz e Terra, 2011.

FREIRE, P. Pedagogia da indignação. São Paulo: Paz e Terra, 2014. 
HERCULANO, S. Riscos e desigualdades sociais: a temática da justiça ambiental e sua construção no Brasil. I Encontro da ANPPAS. Indaiatuba: ANPPAS, 2002.

LAYRARGUES, P.P. Para que a Educação Ambiental encontre a educação. In: LOUREIRO, C.F.B. (org). Trajetória e fundamentos da educação ambiental. 2. ed. São Paulo Cortez, 2006.

LAYRARGUES, P.P. Subserviência ao capital: educação ambiental sob o signo do antiecologismo. Pesquisa em Educação Ambiental. São Paulo, v. 13, n. 1, p. 28-47, 2018. DOI: https://doi.org/10.18675/2177-580x.vol13.n1.p28-47.

LEFF, H. Ecologia, capital e cultura: racionalidade ambiental, democracia participativa e desenvolvimento sustentável. Blumenau: Edifurb, 2000. DOI: https://doi.org/10.1590/s1414-753x2000000100010.

LOUREIRO, C.F.B. Trajetória e fundamentos da educação ambiental. 2. ed. São Paulo Cortez, 2006.

PINTO, A.V. Consciência e realidade nacional. v. 2. Rio de Janeiro: ISEB/MEC, 1960. 